\title{
Design and operation of gas-liquid slug flow in miniaturized channels for rapid mass transfer
}

\section{AUTHOR(S):}

Aoki, Nobuaki; Tanigawa, Shin; Mae, Kazuhiro

\section{CITATION:}

Aoki, Nobuaki ... [et al]. Design and operation of gas-liquid slug flow in miniaturized channels for rapid mass transfer. Chemical Engineering Science 2011, 66(24): 6536-6543

\section{ISSUE DATE:}

2011-12

URL:

http://hdl.handle.net/2433/149655

\section{RIGHT:}

(C) 2011 Elsevier Ltd.; This is not the published version. Please cite only the published version.; この論文は出版社版でありません。引用の際に は出版社版をご確認ご利用ください。 
[Full Length Paper]

Design and operation of gas-liquid slug flow in miniaturized channels for rapid mass transfer

Nobuaki Aoki*, Shin Tanigawa, Kazuhiro Mae

Department of Chemical Engineering, Graduate School of Engineering, Kyoto University, Kyoto-daigaku Katsura, Nishikyo-ku, Kyoto 615-8510, Japan

* Corresponding author. Tel.: +81 75383 2698; fax: +81 753832638.

E-mail address: aoki@ cheme.kyoto-u.ac.jp (N. Aoki) 


\section{Abstract}

The influences of operating parameters such as channel size, flow rate, and void fraction on the mass transfer rate in the gas-liquid slug flow are investigated to establish a design method to determine the parameters for rapid mass transfer. From the experimental results, the turnover index, including the slug linear velocity, its length, and the channel size that represents the turnover frequency of the internal circulation flow, is proposed. For PTFE tube in which no liquid film exists in slug flow, a master curve is derived from the relationship between the mass transfer coefficient and the turnover index. For each channel material, the Sherwood number is also roughly correlated with the Peclet number. These correlations make it possible to arbitrarily determine a set of operating parameters to achieve the desired mass transfer rate. However, the turnover index and the Peclet number include the slug length, which cannot be controlled directly. The relationship between the slug length and the operating parameters is also investigated. The slug volume mainly depends on the inner diameter (i.d.) of a union tee. At a fixed union tee i.d., the slug length is controlled through the exit i.d. of channel connected to the union tee and the void fraction. Thus, the final slug length depends on the union tee and exit channel inner diameters. At low flow rates, the gas and liquid collision angle is significant in determining the slug length.

Keywords: Slug flow; Mass transfer; Microchannel; Multiphase reactors; Design; Absorption 


\section{Introduction}

Gas-liquid two-phase flow is widely used in industrial processes such as organic synthesis and composition separation. Owing to the mutually immiscible character of the two fluids, rapid mass transfer is essential for maximizing the efficiency of these processes.

For this reason, unit operations with miniaturized channels may be used. Miniaturized channels, such as microchannels whose sizes are in the order of sub-millimeters to millimeters, are capable of achieving precisely controlled flow operations through ordered laminar flow (Aoki and Mae, 2006; Aoki et al., 2007; Minagawa et al., 2001; Nagasawa and Mae, 2006; Nisisako, 2008; Serra and Chang, 2008). Channel miniaturization also leads to a high surface-area-to-volume ratio, resulting in enhanced interaction between the channel wall and the fluid as well as between immiscible fluids. This laminar flow and enhanced interaction in miniaturized channels allow the formation of slug flow. In slug flow, fluids of two or more immiscible phases such as gas-liquid and organic-aqueous phases flow alternately. Microchannels with simple shapes such as T-shaped junctions are used to form stable gas-liquid slug flow (Fu et al., 2010; Yun et al., 2010). Given that slugs in the channel move as in a periodic plug flow, a narrow residence time distribution can be precisely achieved (Song et al., 2003; Trachsel et al., 2005). Internal circulation flow in a slug derived from the friction between the channel wall and the fluid in the slug owing to a high surface-area-to-volume ratio is expected to enhance the rate of mixing, which is mainly driven by molecular diffusion in laminar flow (Günther et al., 2005; Kashid et al., 2005; Tanthapanchakoon et al., 2006a, 2006b). Moreover, the internal circulation flow in slugs intensifies the mass transfer between the two phases, since the concentration near the interface is renewed by the flow (Harries et al., 2003). For these reasons, gas-liquid slug flow can be used in various unit operations such as gas absorption and multiphase syntheses (Jähnisch et 
al., 2000; Yasukawa et al., in press).

In conventional research on microdevices, the focus has been on proposing devices with design parameters such as channel size and geometry and operating conditions determined intuitively. However, microdevices developed in an intuitive manner lack versatility. To use microdevices in industrial processes, it is necessary to establish a design method based on a microdevice design equation and indices expressing the characteristics of phenomena in the device. Thus, operating parameters of microdevices correlate with product throughput and quality on the basis of phenomena in the devices. For liquid-liquid slug flow, we have proposed indices for the mixing rate in a slug (Matsuyama et al., 2007; Tanthapanchakoon et al., 2006a, 2006b) and the mass transfer rate between immiscible phases (Aoki et al., 2011).

In developing design guidelines for rapid mass transfer using gas-liquid slug flow, the present research addresses the effects of operating parameters such as channel size, volume flow rate, void fraction, channel material, and gas-liquid collision angle on the mass transfer rate and then establishes an index for selecting the operating parameters with the desired mass transfer rate in slug flow. Carbon dioxide absorption in alkaline solutions is carried out to illustrate an absorption process accompanied by a rapid chemical reaction.

\section{Experimental}

We executed the absorption of $\mathrm{CO}_{2}$ in $0.1 \mathrm{M} \mathrm{NaOH}$ water solution as a model system to evaluate mass transfer efficiency in gas-liquid slug flow. A schematic of the experimental setup is shown in Fig. 1. PTFE tubes with an inner diameter $d$ and length $L$ were connected to the entrances and exit of a union tee (Swagelok) made of SUS with an inner diameter $d_{\mathrm{T}}$. Table 1 lists the combinations of $d$ and $d_{\mathrm{T}}$ for each union tee of outer diameter (o.d.) used in 
the experiments. Pure $\mathrm{CO}_{2}$ was fed into one entrance of the union tee, and the $\mathrm{NaOH}$ solution was fed into the other entrance. The flow rate of $\mathrm{CO}_{2}$ gas was controlled using a mass flow controller (MODEL 3660, KOFLOC). The $\mathrm{NaOH}$ solution was supplied to a union tee by a syringe pump (PHD2000, Harvard Apparatus) through PTFE tubes. Gaseous $\mathrm{CO}_{2}$ was absorbed into the liquid phase and then reacted with $\mathrm{NaOH}$ in the outlet tube at atmospheric pressure. A liquid sample $(2 \mathrm{~mL})$ from the exit was sampled in a beaker. The two phases immediately separated at the exit of the PTFE tube. The experiments were carried out at room temperature (approximately $297 \mathrm{~K}$ ). The amount of absorbed $\mathrm{CO}_{2}$ was determined by neutralization titration. In this experiment, the outlet channel length $L$ was changed to vary the residence time. The ratio of gas volume flow rate $V_{\mathrm{g}}$ to that of liquid phase $V_{1}$ was 1,2 , or 3 . In other words, the void fraction $\alpha\left(=V_{\mathrm{g}} /\left(V_{\mathrm{g}}+V_{1}\right)\right)$ was $0.50,0.67$, or 0.75 . The effect of the total flow rate $\left(V_{\mathrm{g}}+V_{\mathrm{l}}\right)$ was also examined. This procedure of sampling and measuring the amount of absorbed $\mathrm{CO}_{2}$ was repeated three times for each experimental condition, and the average values of $C_{\mathrm{R}}$ (the amount of absorbed $\mathrm{CO}_{2}$ by unit volume) were used to obtain the mass transfer coefficient, given in Section 3.2. The flow information was also identified. The flow pattern in the outlet tube was photographed, and the lengths of liquid phase slugs in the exit channel, $l$, were measured with image processing software ImageJ $(\mathrm{NIH})$. From the image processing, the liquid slug volume was also calculated. The average values were used as resultant lengths. In addition, using a pressure sensor connected at the liquid phase inlet of each union tee (AP-13S, KEYENCE, denoted by PE in Fig. 1), the pressure drop of the slug flow was also measured.

The effects of channel material were also confirmed. Glass tubes of internal diameter (i.d.) $1.0 \mathrm{~mm}$ and $1.6 \mathrm{~mm}$ were connected to the outlets of the union tees of $1 / 16$ " $(1.6 \mathrm{~mm})$ and 1/8" (3.2 mm)-o.d., respectively. 
The effects of the gas-liquid collision angle in the union tee on the slug size were also investigated. The examined collision angles are illustrated in Fig. 2. In the operation shown in Fig. 2(a) (the same as that shown in Fig. 1), we call the collision angle " $180^{\circ}$ horizontal." Gas and liquid collide from opposing directions. In the collision shown in Fig. 2(b), the angle is called " $90^{\circ}$ horizontal." For these two angles, the union tee was placed horizontally. Moreover, the union tee was set vertically to examine the effect of gravity, as shown in Fig. 2(c). The angle here is called " $90^{\circ}$ vertical." In the experiments on the three angles, the union tee of $d_{\mathrm{T}}=2.4 \mathrm{~mm}$ and $d=2 \mathrm{~mm}$ and the condition of $\alpha=0.67$ were employed.

\section{Results and discussion}

\subsection{Effects of operating conditions on the rate of $\mathrm{CO}_{2}$ absorbance}

\subsubsection{Void fraction}

Fig. 3 shows the relationships between the amount of absorbed $\mathrm{CO}_{2}$ and the exit channel length for each void fraction with a fixed total volume flow rate and each flow rate with a fixed void fraction $\left(d_{\mathrm{T}}=2.3 \mathrm{~mm}, d=1.59 \mathrm{~mm}\right)$. The plots in the figures correspond to the average measured concentrations, and the error bars show the highest and lowest measured concentrations. The deviation of measured concentrations from the average is less or equal to $9 \%$. Hereafter, the results are obtained from the stable slug flow operation. Comparing the values of $C_{\mathrm{R}}$ of the same total flow rate shown in Fig. 3(a), we find that the rate of absorbance slightly increases with increasing value of $\alpha$. When $\alpha=0.50\left(V_{\mathrm{g}} / V_{1}=1\right)$, since the amount of fed $\mathrm{CO}_{2}$ is less than that calculated from the stoichiometric ratio $\left(V_{\mathrm{g}} / V_{1}=\right.$ 2.4 is needed for the ratio), $\mathrm{CO}_{2}$ is completely consumed in the exit channel. Therefore, the 
increase in $C_{\mathrm{R}}$ ceased at the dashed line $\left(C_{\mathrm{R}}=0.41 \mathrm{~mol} \cdot \mathrm{L}^{-1}\right)$ in Figs. 3(a) and (b). The approximate residence time for complete consumption of $\mathrm{CO}_{2}$ was $15 \mathrm{~s}$ for $\alpha=0.50$ and $V_{\mathrm{g}}=$ $V_{1}=6 \mathrm{~mL} \cdot \mathrm{min}^{-1}$. The channel length needed to achieve a fixed value of $C_{\mathrm{R}}$ gradually increases with the total flow rate for each void fraction. However, because the linear velocity increases with the total flow rate, the residence time required to achieve a fixed value of $C_{\mathrm{R}}$ decreases with the rate. Because the gas volume flow rate and the linear velocity vary with the progress of mass transfer, the residence time is not proportional to the channel length. Thus, quantitative comparison of the mass transfer rate is difficult through these figures. Thus, the relationship between $C_{\mathrm{R}}$ and the residence time is given in Section 3.2.1.

\subsubsection{Channel size}

Fig. 4 shows the relationship between $C_{\mathrm{R}}$ and $L$ for each exit channel diameter. The value of $C_{\mathrm{R}}$ for $d=1.00 \mathrm{~mm}$ is larger than that for $d=1.59 \mathrm{~mm}$. The plots in this figure correspond to the average measured concentrations, and the error bars show the highest and lowest measured concentrations. The deviation of measured concentrations from the average is less or equal to $7 \%$. Smaller channels lead to enhanced linear velocity and circulation flow in slugs at a fixed flow rate and higher surface-area-to-volume ratio. In addition, the slug volume and length decrease with reducing channel i.d. The flow path length inside a slug also decreases. This results in an enhanced frequency of fluid circulation and renewal of concentration of reactants. The effect of channel i.d. on the slug length is discussed in Section 3.3. At a fixed channel length, the value of $C_{\mathrm{R}}$ for $d=2.00 \mathrm{~mm}$ is comparable to that for $d=$ $1.00 \mathrm{~mm}$. The cross-sectional area for the former channel is four times larger that that for the latter, and the residence time is also longer. Therefore, the mass transfer rate of $d=2.00 \mathrm{~mm}$ is much lower than that of $d=1.00 \mathrm{~mm}$. The value of $C_{\mathrm{R}}$ for $d=2.00 \mathrm{~mm}$ is higher than that for $d=1.59 \mathrm{~mm}$ at the same channel length. Thus, the effect of increase in the residence time 
is more dominant than that of the increase in the channel size for a larger channel size.

As shown in these two subsections, the relationship between the mass transfer rate and the operating conditions is complicated. To intuitively compare the mass transfer of different channel sizes and the total flow rate, we obtain the mass transfer coefficient in Section 3.2.2.

\subsubsection{Channel material}

Fig. 5 shows the relationship between $C_{\mathrm{R}}$ and $L$ for PTFE and glass exit channels. Mass transfer in the glass channel is faster than that in the PTFE channel. This tendency is explained using the slug shape for each channel material. The slug shape depends on the channel surface hydrophilicity, as shown in Fig. 6. When the channel surface is PTFE and hydrophobic, only the front and back of the gas phase slugs contact with the liquid slugs (Fig. 6(a)). When the channel surface is glass and hydrophilic, the channel surface is always wetted by the liquid phase. Therefore, the gas phase slug is completely surrounded by the liquid phase (Fig. 6(b)). Thus, the contact surface area between the gas and the liquid phases for the glass channel is larger than that for the PTFE tube. The existence of the liquid film in the glass tube is confirmed from the deference in the pressure drop in the glass and PTFE tubes as shown in Fig. 7. The glass tube gives lower pressure drop than the PTFE tube. This is because the liquid film acts as lubricant for gas slugs. The pressure drop in the glass tube is comparable to that of the flow of only water estimated from the Hagen-Poiseuille equation.

\subsection{Mass transfer coefficient}

\subsubsection{Mass transfer model for determining mass transfer coefficient}

To quantitatively evaluate the mass transfer rate, the liquid film mass transfer 
coefficient $k_{\mathrm{L}}$ is needed. We therefore establish a model for obtaining $k_{\mathrm{L}}$ from the experimental results. In this model, we hypothesize the following. The volume of liquid phase slug (also $v_{\mathrm{L}}$ ), the value of $k_{\mathrm{L}}$, the specific interface area, and the temperature are constant in the channel; neither coalescence nor breakup of slugs occurs; and Henry's law is applied at the gas-liquid interface. The overall reaction of $\mathrm{CO}_{2}$ absorption in the base solution is represented as follows (Zanfir et al., 2005):

$$
\begin{aligned}
& \mathrm{CO}_{2}(\mathrm{~g})+2 \mathrm{OH}^{-}(\mathrm{l}) \rightarrow \mathrm{CO}_{3}{ }^{2-}(\mathrm{l})+\mathrm{H}_{2} \mathrm{O}(\mathrm{l}) \\
& \mathrm{A}(\mathrm{g})+2 \mathrm{~B}(\mathrm{l}) \rightarrow \mathrm{R}(\mathrm{l})+\mathrm{S}(\mathrm{l})
\end{aligned}
$$

Hereafter, the expression in Eq. (2) is used for the subscripts of variables. This reaction completes rapidly (Ziegenbalg et al., 2010); the gas phase is pure $\mathrm{CO}_{2}$, and no concentration gradient is present in the gas phase. Therefore, the mass transfer in the liquid film is the rate-controlling step. Under this condition, the mass transfer flux of $\mathrm{A}, N_{\mathrm{Ai}}$, is given by

$$
N_{\mathrm{A}}=k_{\mathrm{L}} C_{\mathrm{Ai}}\left(1+D_{\mathrm{B}} C_{\mathrm{BL}} / 2 D_{\mathrm{A}} C_{\mathrm{Ai}}\right)
$$

where $C_{\mathrm{Ai}}$ is the concentration of $\mathrm{A}\left(\mathrm{CO}_{2}\right)$ in the liquid interface, $C_{\mathrm{BL}}$ is the bulk concentration of $\mathrm{B}\left(\mathrm{OH}^{-}\right)$, and $D_{\mathrm{A}}$ and $D_{\mathrm{B}}$ are the diffusivity of $\mathrm{A}$ and $\mathrm{B}$ in the liquid phase, respectively; $D_{\mathrm{A}}$ $=1.77 \times 10^{-9} \mathrm{~m}^{2} \cdot \mathrm{s}^{-1}$, and $D_{\mathrm{B}}=5.23 \times 10^{-9} \mathrm{~m}^{2} \cdot \mathrm{s}^{-1}$ (Zanfir et al., 2005). In the experiments, pure $\mathrm{CO}_{2}$ gas was used, and therefore, the pressure of $\mathrm{A}$ in the liquid interface is equal to that of the bulk gas phase $p$. Because of the mass transfer controlled condition, the rate of formation of $\mathrm{R}$ $\left(\mathrm{CO}_{3}{ }^{2-}\right)$ in a liquid slug is expressed as

$$
\mathrm{d} C_{\mathrm{R}} / \mathrm{d} t=N_{\mathrm{A}} a
$$

where $C_{\mathrm{R}}$ is the concentration of $\mathrm{R}$ in the liquid phase (the same as the amount of absorbed $\mathrm{CO}_{2}$ by unit volume), $t$ is the residence time, and $a$ is the specific interface area used for mass transfer. The interface area was determined using the photographs taken in the experiments under the assumption that the interface shape is a paraboloid of revolution. The material balance is given by 


$$
C_{\mathrm{R}}=\frac{C_{\mathrm{BL} 0}-C_{\mathrm{BL}}}{2}
$$

The subscript 0 denotes the inlet condition. The value of $C_{\mathrm{BL} 0}$ is equal to the concentration of the prepared solution $(0.1 \mathrm{M})$. The flow condition is calculated from the following equations:

$$
\begin{aligned}
& \frac{d z}{d t}=U=\frac{v_{\mathrm{G}}+v_{\mathrm{L}}}{S} \\
& v_{\mathrm{G}}=\frac{F_{\mathrm{A}}}{F_{\mathrm{A} 0}} \frac{p_{0}}{p} v_{\mathrm{G} 0} \\
& p=p_{0}+\left(\frac{d p}{d z}\right) z
\end{aligned}
$$

where $z$ is the axial position of a liquid slug, $v_{\mathrm{G}}$ and $v_{\mathrm{L}}$ are the gas and liquid volume flow rates, respectively, $S$ is the cross-sectional area of the exit channel, and $F_{\mathrm{A}}$ is the molar flow rate of gaseous $\mathrm{CO}_{2}$. The gas volume flow rate decreases as the mass transfer progresses. The value of $p_{0}$ is obtained from the measurement using the pressure sensor in the experiments. The slope of pressure change $d p / d z$ is calculated from the measured pressure. Fig. 8 shows an example of the measured pressure drop with a fixed outlet channel length $(L=30 \mathrm{~cm})$. For the PTFE tube, the pressure drop is higher than that of the flow of only water estimated from the Hagen-Poiseuille equation. This tendency indicates that the multiple gas/liquid plugs on the channel wall enhances the friction loss. Because of the increase in the fraction of lower viscosity fluid, namely air, the pressure drop decreases with increasing $\alpha$.

The amount of absorbed $\mathrm{CO}_{2}$ as a function of $t$ is calculated from Eqs. (3)-(8) and the assumptions. The value of $k_{\mathrm{L}}$ and the concentration of $\mathrm{R}$ at $t=0 \mathrm{~s}, C_{\mathrm{R} \mid t=0}$, were fitted so that the experimental and calculated values of $C_{\mathrm{R}}$ in the outlet of the exit channel were consistent using the simplex method. Fig. 9 shows an example of the fitting result. In Section 3.2.2, the overall relationship between $k_{\mathrm{L}}$ obtained here and the operating parameters is derived. Fig. 10 shows the relationship between $C_{\mathrm{R}}$ and the residence time for the results shown in Fig. $3\left(V_{\mathrm{g}} / V_{1}=1\right)$. As shown in Figs. 9 and 10 , the values of $C_{\mathrm{R}}$ at $t=0 \mathrm{~s}$ (fitted 
value of $C_{\mathrm{R} 0}$ ) are not equal to zero. This indicates that the $\mathrm{CO}_{2}$ absorption occurs at the moment of slug formation to some extent.

\subsubsection{Relationship between the mass transfer coefficient and the operating parameters}

For each void fraction with a fixed channel i.d., Fig. 11 shows the mass transfer coefficient obtained from the model calculation described in Section 3.2.1. For the $x$-axis, the slug velocity corresponding to the total flow rate is also given. The coefficient rises with the total flow rate and linear flow velocity. The mass transfer rate also slightly increases with void fraction. This tendency is attributed to the decrease in the liquid slug length, which is described later in Section 3.3. Higher linear velocity and short slug length lead to an enhanced circulation of fluid inside a slug. These result in increased mass transfer rate.

The effect of channel i.d. on the mass transfer coefficient is given in Fig. 12. The coefficient increases with decreasing channel i.d. Small channel and union tee provide small slug, which gives a high surface area to volume ratio and a short fluid pass length inside a slug.

\subsubsection{Derivation of the turnover index for predicting the mass transfer efficiency}

The effects of the operating parameters such as the flow rate (slug linear velocity), void fraction, and channel sizes on the mass transfer rate have been described in Section 3.1. From these results, the mass transfer coefficient was obtained using the model given in Section 3.2.1. To design the mass transfer procedure based on gas-liquid slug flow with the desired transfer rate, the overall relationship between the operating parameters and the mass transfer coefficient needs to be determined. From the tendency shown in Section 3.2.2, the mass transfer coefficient increases with increasing flow velocity and decreasing fluid path 
length in a slug. We therefore consider an index to correlate the operating parameters and $k_{\mathrm{L}}$. The index is denoted by $U_{0} /(d+2 l)$, where $U_{0}$ is the initial linear velocity. The length denoted by $d+2 l$ represents the length of the circulation path for the internal circulation flow inside a slug. The value of $U_{0} /(d+2 l)$ represents the turnover frequency of fluid in a slug. Fig. 13 shows the relationship between the turnover index, $U_{0} /(d+2 l)$, and the mass transfer rate, $k_{\mathrm{L}}$, for the results obtained using the PTFE tubes. The value of $k_{\mathrm{L}}$ improves with an increase in $U_{0} /(d+2 l)$. Increasing the slug velocity $\left(U_{0}\right)$ and decreasing the slug length leads to a higher index value, which is consistent with the results presented in Section 3.2.1. The circulation flow inside a slug renews the concentration at the phase interface more efficiently with higher $U_{0} /(d+2 l)$. In addition, plots of $k_{\mathrm{L}}$ are on the same line, shown by the solid line in Fig. 13, regardless of channel size, linear velocity, and void fraction. This line is the master curve of the mass transfer rate and includes the effects of operating parameters. We can therefore determine the channel size and the flow rate to obtain the desired mass transfer rate by choosing an appropriate value for the turnover index, $U_{0} /(d+2 l)$, from the master curve.

Fig. 14 shows the relationship between $k_{\mathrm{L}}$ and the turnover index for the results obtained using glass tubes. The master curve for the PTFE tube is shown by the solid line. The values given by the solid plots in the figure are calculated under the assumption that only the front and back of the slug interface is considered as the interface area for mass transfer. Those given next to the outlined plots are calculated with the assumption that the entire surface of the liquid slug is considered as the interface area. The values of solid plots at a fixed turnover index are higher than those obtained from the master curve. In contrast, those of the outlined plots are lower. These results suggest that the interface near the channel wall is also used for mass transfer; however, the contribution of the interface at the front and back of the slug is larger than that at the interface near the channel wall. This is why the correlation is not seen for the glass tube. Fig. 14 thus shows that the master curve is valid only for a channel 
material in which no liquid film exists.

\subsubsection{Correlation of the mass transfer coefficient using dimensionless groups}

In the previous section, the mass transfer coefficient is correlated with the turnover frequency. However, both coefficient and frequency have dimensions. Moreover, this correlation is valid only for the PTFE tube in which no liquid film exists. We then correlated the mass transfer rate using dimensionless groups. The Sherwood number $\left(S h=k_{\mathrm{L}} d / D_{\mathrm{A}}\right)$ and the Peclet number $\left(\mathrm{Pe}=U_{0} l / D_{\mathrm{A}}\right)$ were chosen because the slug flow conditions, that is, the slug length $l$, channel i.d. $d$, and the slug velocity $U_{0}$, and the mass transfer coefficient $k_{\mathrm{L}}$ are included in these groups. Fig. 15 shows the relationship between the Sherwood number and $P e$. The values of $k_{\mathrm{L}}$ for the glass tube are calculated under the assumption that only the front and back of the slug interface is considered as the interface area for mass transfer. From this figure, the mass transfer rate of each channel material can be correlated roughly. This result also indicates that the internal circulation, especially for the axial direction, is significant on determining the mass transfer rate.

\subsection{Control of slug length}

The turnover index and the Peclet number include the slug length. Unlike the channel i.d. and slug linear velocity, we cannot directly choose the slug length, because the slug size depends on operating conditions. We thus derive the relationship between the operating parameter conditions and the slug length. As operating parameters, the effects of the channel i.d., the void fraction, and the angle of confluence of gas and liquid are examined. 


\subsubsection{Effects of collision angle and flow rate}

Fig. 16 shows the relationship of the liquid slug length and the total flow rate for each collision angle $(\alpha=0.67)$. At low flow rates, $90^{\circ}$ is effective in reducing the slug length. This is because the shear force applied to the liquid phase is large at the point at which gas and liquid collide. With similar slug lengths of $90^{\circ}$ vertical and horizontal, the effect of gravity is small in the small channels. The difference in the collision angle decreases with an increase in the total flow rate. For all collision angles, the slug length is approximately constant in a high flow rate range.

\subsubsection{Effects of channel size and void fraction}

Fig. 17 shows the liquid slug volume formed with various exit channel diameters and void fractions. Fig. 18 shows the corresponding liquid slug length. The plots were obtained in a high flow rate range where the change in slug size is small. The slug volume decreases linearly with the void fraction. However, the slug volume depends more strongly on the i.d. of the union tee. For example, the slug volume of $d_{\mathrm{T}}=2.4 \mathrm{~mm}, d=2 \mathrm{~mm}$, and $\alpha=0.50$ is approximately 10 times larger than that of $d_{\mathrm{T}}=1.3 \mathrm{~mm}, d=0.75 \mathrm{~mm}$, and $\alpha=0.50$. For larger channels, the slug volumes are approximately the same for the results of the union tees of 1/8"- and 3 mm-o.d. with different exit channel diameters $(d=1.59$ and $2.00 \mathrm{~mm})$. These results suggest that the slug volume depends on the i.d. of the union tee rather than on the exit channel i.d. Thus, the slug volume is determined at the instance of slug formation. To control the slug length, first the i.d. of the union tee and then that of the exit channel should be determined. This guideline is particularly effective for larger channels.

From the results presented in Section 3.3, the dependence of slug length on the operating parameters can be summarized as follows. The slug volume mainly depends on the 
i.d. of the union tee. This is particularly true at high flow rates. The slug length is controlled through the exit channel i.d. and the void fraction. At low flow rates, the collision angle of $90^{\circ}$ is effective in shortening the slug length.

\section{Conclusions}

We have investigated the relationship between the mass transfer rate and the operating parameters such as channel size and flow rate to establish the design guidelines for mass transfer operations using gas-liquid slug flow. On the basis of the experimental results, we derived a turnover index, including the slug linear velocity, its length, and the channel size that represents the turnover frequency of the internal circulation flow. For a channel material in which no liquid film exists in slug flow, a master curve has been derived from the relationship between the mass transfer coefficient and the turnover index. For each channel material, the Sherwood number is roughly correlated with the Peclet number. These correlations make it possible to arbitrarily determine a set of operating parameters to achieve the desired mass transfer rate. However, the turnover index and the Peclet number include the slug length, which cannot be controlled directly. The relationship between the slug length and the operating parameters has also been investigated. From the results obtained, the dependence of the slug length on the operating parameters can be summarized as follows. The slug volume mainly depends on the i.d. of the union tee; this is particularly true at high flow rates. The slug length is controlled through the i.d. of exit channel connected to the union tee, and the void fraction. At low flow rates, the gas-liquid collision angle is significant in determining the slug length. The collision angle of $90^{\circ}$ is effective in shortening the slug length.

The mass transfer rate can be controlled precisely by selecting appropriate operating 
parameters using the turnover index. In addition, axial dispersion is prevented in slug flow, and temperature control is facilitated in miniaturized channels. Slug flow in miniaturized channels therefore enables precisely controlled and rapid mass transfer and reaction procedures and thus enhances the efficiency of such processes.

\section{Acknowledgement}

The authors gratefully acknowledge the financial support of the New Energy and Industrial Technology Development Organization (NEDO) through the "Development of Fundamental Technologies for Green and Sustainable Chemical Processes Project.”

\section{References}

Aoki, N., Mae, K., 2006. Improvement of product yield and selectivity in microreactors by combining fluid segments of different concentrations and sizes. Studies in Surface Science and Catalysis 159, 641-644.

Aoki, N., Tanigawa, S., Mae, K., 2011. A new index for precise design and advanced operation of mass transfer in slug flow. Chemical Engineering Journal, 167, 651-656.

Aoki, N., Yube, K., Mae, K., 2007. Fluid segment configuration for improving product yield and selectivity of catalytic surface reactions in microreactors. Chemical Engineering Journal 133, 105-111.

Fu, T., Ma, Y., Funfschilling, D., Zhu, C., Li, H.Z., 2010. Squeezing-to-dripping transition for bubble formation in a microfluidic T-junction. Chemical Engineering Science 65, 3739-3748.

Günther, A., Thalmann, M., Jhunjhunwala, M., Schmidt, M.A., Jensen, K.F., 2005. Micromixing of miscible liquids in segmented gas-liquid flow. Langmuir 21, 
$1547-1555$.

Harries, N., Burns, J.R., Barrow, D.A., Ramshaw, C., 2003. A numerical model for segmented flow in micro-reactor. International Journal of Heat and Mass Transfer 46, $3313-3322$.

Jähnisch, K., Baerns, M., Hessel, V., Ehrfeld, W., Haverkamp, V., Löwe, H., Wille, Ch., Guber, A., 2000. Direct fluorination of toluene using elemental fluorine in gas/liquid microreactors. Journal of Fluorine Chemistry 105, 117-128.

Kashid, M.N., Gerlach, I., Goetz, S., Franzke, J., Acker, J.F., Platte, F., Agar, D.W., Turek, S., 2005. Internal circulation within the liquid slugs of a liquid-liquid slug-flow capillary microreactor. Industrial \& Engineering Chemistry Research 44, 5003-5010.

Matsuyama, K., Tanthapanichakoon, W., Aoki, N., Mae, K., 2007. Operation of microfluidic liquid slug formation and slug design for kinetics measurement. Chemical Engineering Science 62, 5133-5136.

Minagawa, T., Tokeshi, M., Kitamori, T., 2001. Integration of a wet analysis system on a glass chip: determination of $\mathrm{Co}$ (II) as 2-nitroso-1-naphthol chelates by solvent extraction and thermal lens microscopy. Lab Chip 1, 72-75.

Nagasawa, H., Mae, K., 2006. Development of a new microreactor based on annular microsegments for fine particle production. Industrial \& Engineering Chemistry Research 45, 2179-2186.

Nisisako, T., 2008. Microstructured devices for preparing controlled multiple emulsions. Chemical Engineering Technology 31, 1091-1098.

Serra, C.A., Chang, Z., 2008. Microfluidic-assisted synthesis of polymer particles. Chemical Engineering Technology 31, 1099-1115.

Song, H., Tice, J.D., Ismagilov, R.F., 2003. A microfluidic system for controlling reaction networks in time. Angewandte Chemie International Edition 42, 768-772. 
Tanthapanichakoon, W., Aoki, N., Matsuyama, K., Mae, K., 2006a. Design of mixing in microfluidic liquid slugs based on a new dimensionless number for precise reaction and mixing operations. Chemical Engineering Science 61, 4220-4232.

Tanthapanchakoon, W., Matsuyama, K., Aoki, N., Mae, K., 2006b. Design of microfluidic slug mixing based on the correlation between a dimensionless mixing rate and a modified Peclet number. Chemical Engineering Science 61, 7386-7392.

Trachsel, F., Günther, A., Khan, S., Jensen, K.F., 2005. Measurement of residence time distribution in microfluidic systems. Chemical Engineering Science 60, 5729-5737.

Yasukawa, T., Ninomiya, W., Ooyachi, K., Aoki, N., Mae, K. Enhanced production of ethyl pyruvate using gas-liquid slug flow in microchannel. Chemical Engineering Journal, in press, DOI: 10.1016/j.cej.2010.08.077.

Yun, J., Lei, Q., Zhang, S., Shen, S., Yao, K., 2010. Slug flow characteristics of gas-miscible liquids in a rectangular microchannel with cross and T-shaped junctions. Chemical Engineering Science 65, 5256-5263.

Zanfir, M., Gavriilidis, A., Wille, Ch., Hessel, V., 2005. Carbon dioxide absorption in a falling film microstructured reactor: experiments and modeling. Industrial Engineering Chemistry Research 44, 1742-1751.

Ziegenbalg, D., Löb, P., Al-Rawashdeh, M., Kralisch, D., Hessel, V., Schönfeld, F., 2010. Use of 'smart interfaces' to improve the liquid-sided mass transport in a falling film microreactor. Chemical Engineering Science 65, 3557-3566. 


\section{List of table and figure captions}

\section{Table 1}

Combinations of channel inner diameters of union tee and exit channel.

Fig. 1. Experimental setup. Slug flow is formed at the outlet of union tee.

Fig. 2. Gas-liquid collision angle. (a) $180^{\circ}$ horizontal, (b) $90^{\circ}$ horizontal, and (c) $90^{\circ}$ vertical.

Fig. 3. $\mathrm{CO}_{2}$ absorbance of (a) each void fraction $\left(V_{\mathrm{g}}+V_{1}=12 \mathrm{~mL} \cdot \mathrm{min}^{-1}\right)$ and (b) each volume flow rate $(\alpha=0.50) . d_{\mathrm{T}}=2.3 \mathrm{~mm}, d=1.59 \mathrm{~mm}$. The plots in the figures correspond to the average measured concentrations, and the error bars show the highest and lowest measured concentrations. The dashed lines in the two graphs denotes the value of $C_{\mathrm{R}}$ for complete absorption for $\alpha=0.50$ (theoretical maximum value).

Fig. 4. $\mathrm{CO}_{2}$ absorbance of each channel size $\left(V_{\mathrm{g}}=6 \mathrm{~mL} \cdot \mathrm{min}^{-1}, V_{1}=3 \mathrm{~mL} \cdot \mathrm{min}^{-1}, \alpha=0.67\right)$. At a fixed channel length, the values of $C_{\mathrm{R}}$ are comparative for $d=1.00 \mathrm{~mm}$ and $2.00 \mathrm{~mm}$. The mean residence time for $d=2.00 \mathrm{~mm}$ is however four times longer than that for $d=1.00 \mathrm{~mm}$.

Fig. 5. $\mathrm{CO}_{2}$ absorbance of each channel material $\left(d_{\mathrm{T}}=2.4 \mathrm{~mm}, d=2.00 \mathrm{~mm}, V_{\mathrm{g}}=6\right.$ $\left.\mathrm{mL} \cdot \min ^{-1}, V_{1}=3 \mathrm{~mL} \cdot \mathrm{min}^{-1}, \alpha=0.67\right)$. In the glass channel, liquid film between the gas slug and the channel wall exists. This film increases the mass transfer rate.

Fig. 6. Slug shapes of (a) hydrophobic (PTFE) and (b) hydrophilic (glass) channels. In the glass channel, liquid film between the gas slug and the channel wall exists.

Fig. 7. Pressure drop of the glass and PTFE tube $\left(d_{\mathrm{T}}=2.4 \mathrm{~mm}, d=2.00 \mathrm{~mm}, V_{\mathrm{g}}=6\right.$ $\mathrm{mL} \cdot \min ^{-1}, V_{1}=3 \mathrm{~mL} \cdot \min ^{-1}, \alpha=0.67$, the outlet channel length $\left.L=30 \mathrm{~cm}\right)$. The lower pressure drop of the glass tube supports the existence of the liquid film.

Fig. 8. Pressure drop as a function of total flow rate $\left(d_{\mathrm{T}}=2.4 \mathrm{~mm}, d=2.00 \mathrm{~mm}, L=30 \mathrm{~cm}\right.$, PTFE tube). The pressure drop is higher than that of single liquid phase estimated from the 
Hagen.

Fig. 9. Example of a fitting result $\left(d_{\mathrm{T}}=2.3 \mathrm{~mm}, d=1.59 \mathrm{~mm}, V_{\mathrm{g}}=V_{1}=4 \mathrm{~mL} \cdot \mathrm{min}^{-1}, \alpha=\right.$ $0.50)$.

Fig. 10. Calculated $C_{\mathrm{R}}$ as a function of residence time $\left(d_{\mathrm{T}}=2.3 \mathrm{~mm}, d=1.59 \mathrm{~mm}, \alpha=0.50\right.$; see Fig. 3). The calculation using the model converts the relationship between $C_{\mathrm{R}}$ and the channel length to that between $C_{\mathrm{R}}$ and the residence time.

Fig. 11. Mass transfer coefficient of each void fraction $\left(d_{\mathrm{T}}=2.3 \mathrm{~mm}, d=1.59 \mathrm{~mm}\right)$.

Fig. 12. Mass transfer coefficient as a function of channel i.d. $\left(V_{\mathrm{g}}=6 \mathrm{~mL} \cdot \mathrm{min}^{-1}, V_{1}=3\right.$ $\left.\mathrm{mL} \cdot \min ^{-1}, \alpha=0.67\right)$.

Fig. 13. Relationship between mass transfer coefficient and turnover index. The mass transfer coefficient increased roughly with the turnover index.

Fig. 14. Relationship between $k_{\mathrm{L}}$ and turnover index for a glass tube. The values given by the solid plots in the figure are calculated under the assumption that only the front and back of the slug interface is considered as the interface area for mass transfer. Those given next to the outlined plots are calculated with the assumption that the entire surface of the liquid slug is considered as the interface area. The mass transfer coefficients deviate from the correlation of the PTFE tube.

Fig. 15. Correlation of Sherwood number $\left(S h=k_{\mathrm{L}} d / D_{\mathrm{A}}\right)$ and Peclet number $\left(P e=U_{0} l / D_{\mathrm{A}}\right)$. For each channel material, $S h$ is roughly correlated with $P e$.

Fig. 16. Slug length for each collision angle $\left(d_{\mathrm{T}}=2.4 \mathrm{~mm}, d=2 \mathrm{~mm}, \alpha=0.67\right)$. For low flow rates, the collision angle is significant on the mass transfer coefficient.

Fig. 17. Relationship between liquid slug volume and void fraction for each channel size. The union tee i.d. dominates the liquid slug volume.

Fig. 18. Relationship between liquid slug length and void fraction for each channel size. The slug length slowly decreases with increasing the void fraction. 


\section{Table 1}

\begin{tabular}{ccc}
\hline $\begin{array}{c}\text { Union tee fitting tube } \\
\text { outer diameter }\end{array}$ & $d_{\mathrm{T}}[\mathrm{mm}]$ & $d[\mathrm{~mm}]$ \\
\hline $1 / 16^{\prime \prime}$ & 1.3 & 0.75 \\
$1 / 16^{\prime \prime}$ & 1.3 & 1.00 \\
$1 / 8 "$ & 2.3 & 1.59 \\
$3 \mathrm{~mm}$ & 2.4 & 2.00 \\
\hline
\end{tabular}




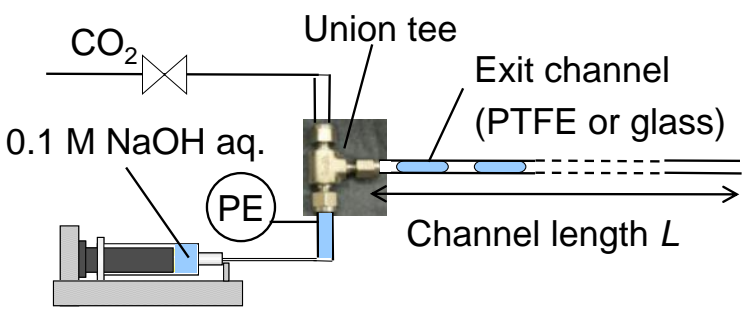

Fig. 1. 


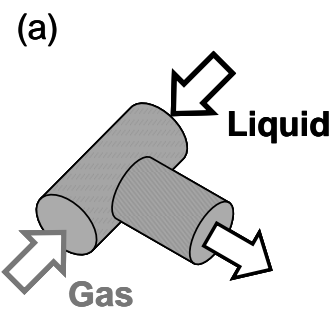

(b)

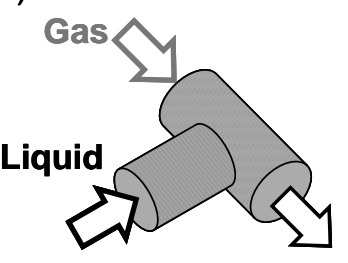

(c)

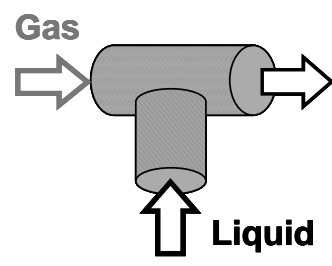

Fig. 2. 

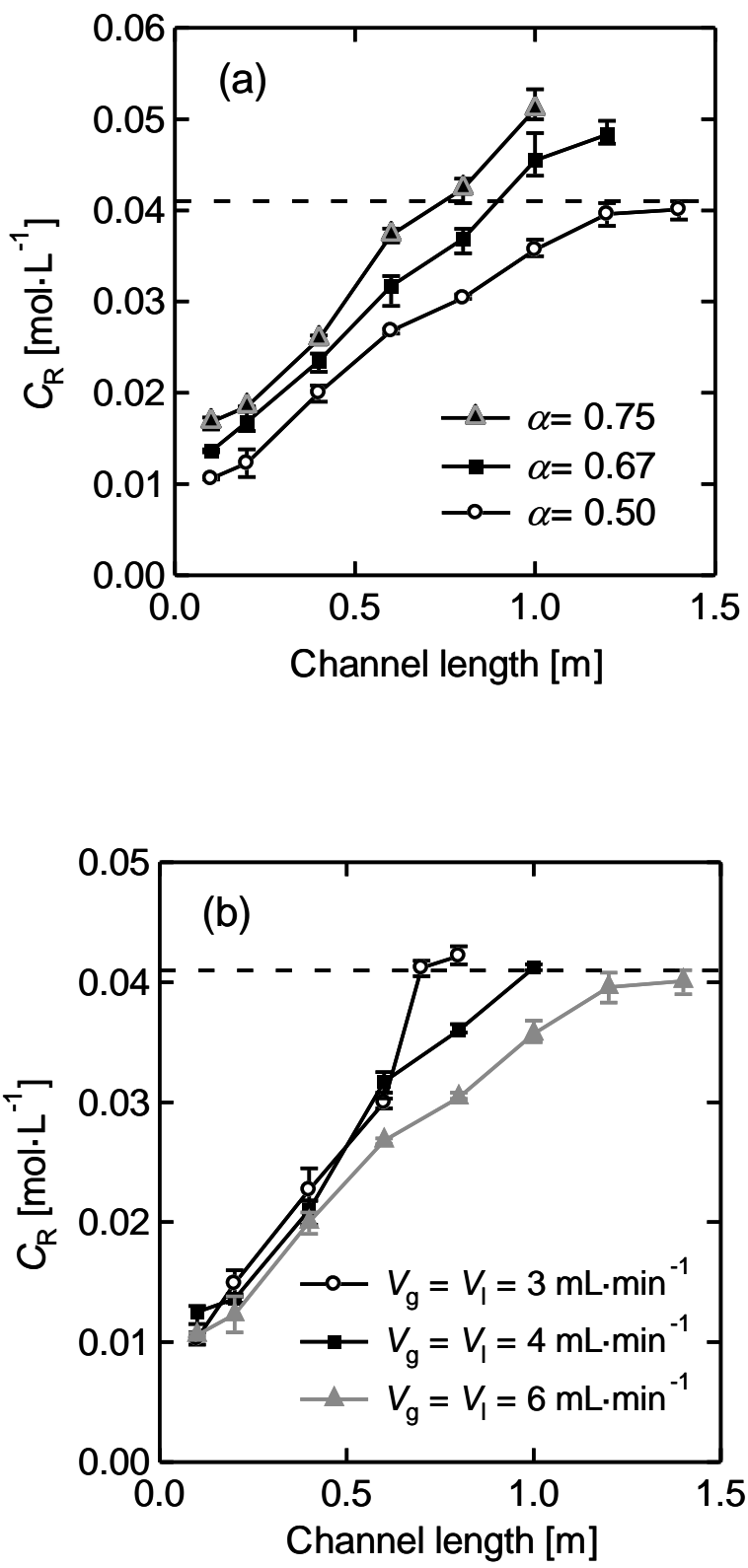

Fig. 3. 


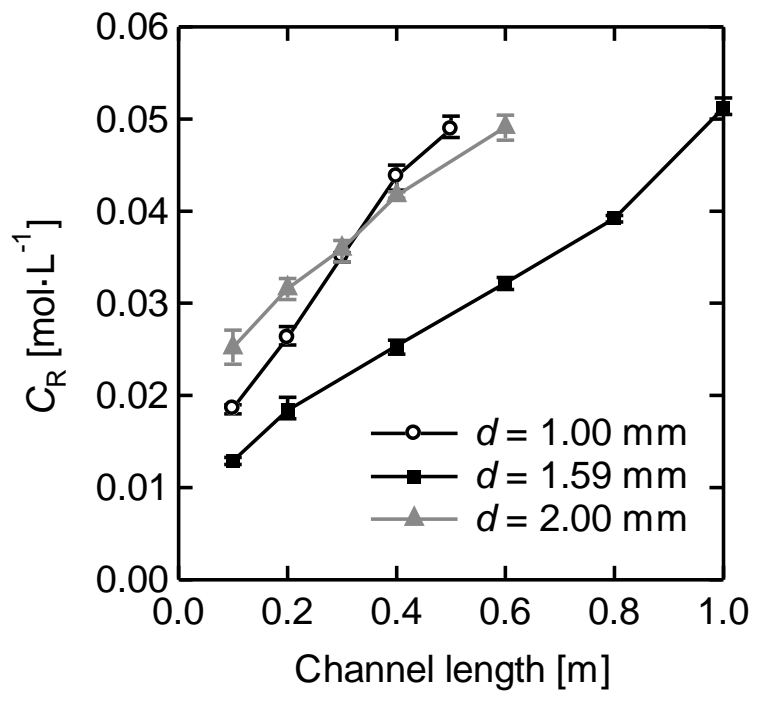

Fig. 4. 


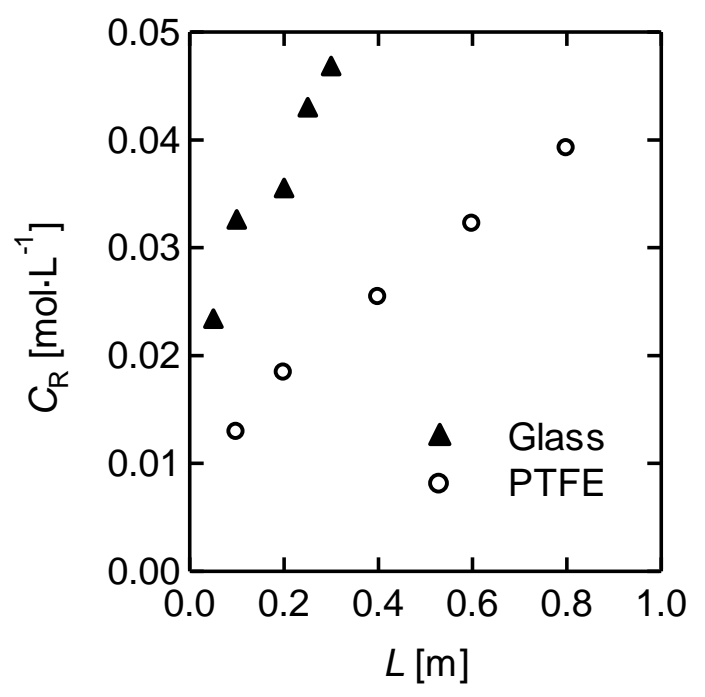

Fig. 5. 


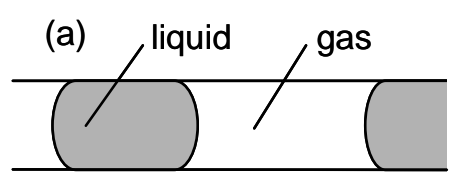

(b)

Fig. 6. 


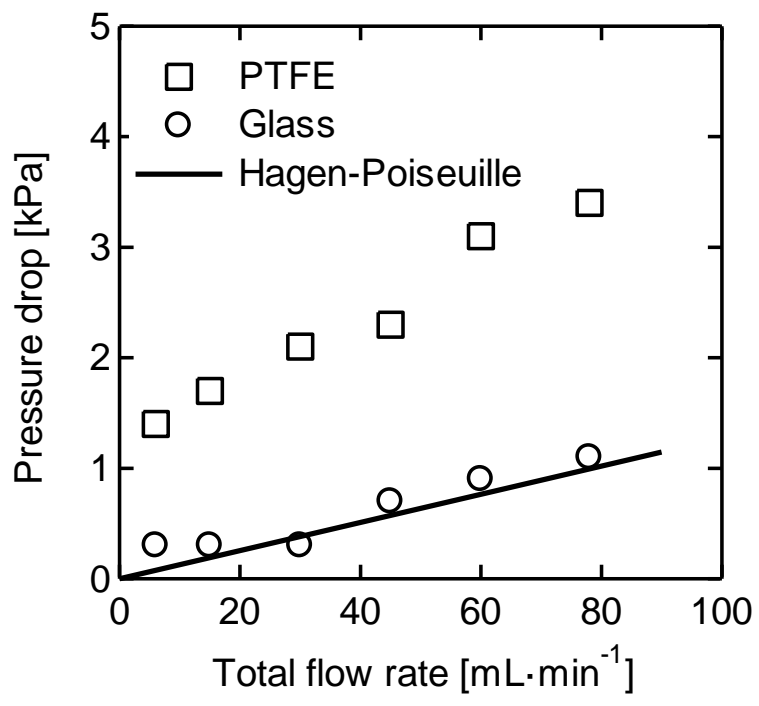

Fig. 7. 


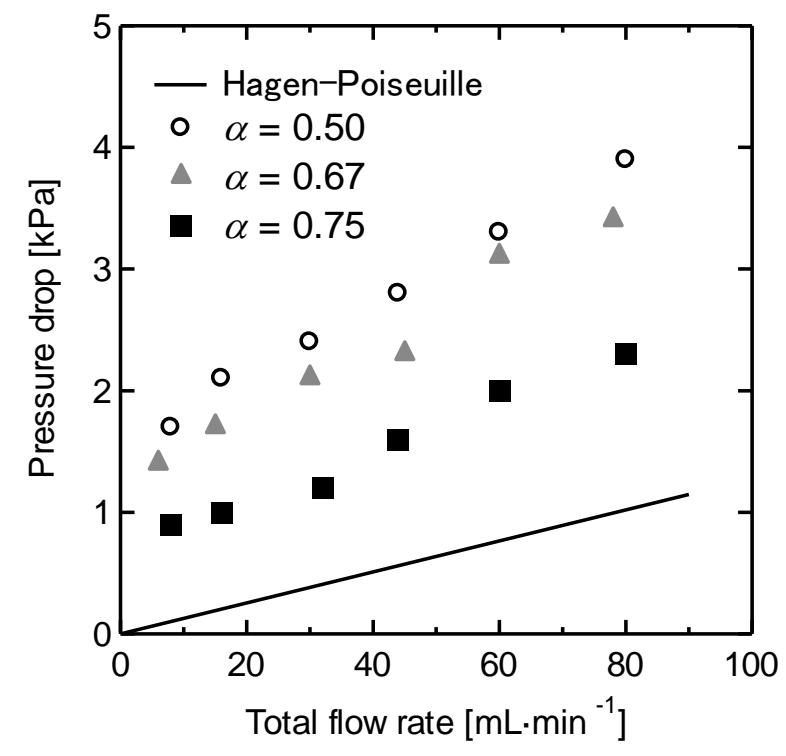

Fig. 8 


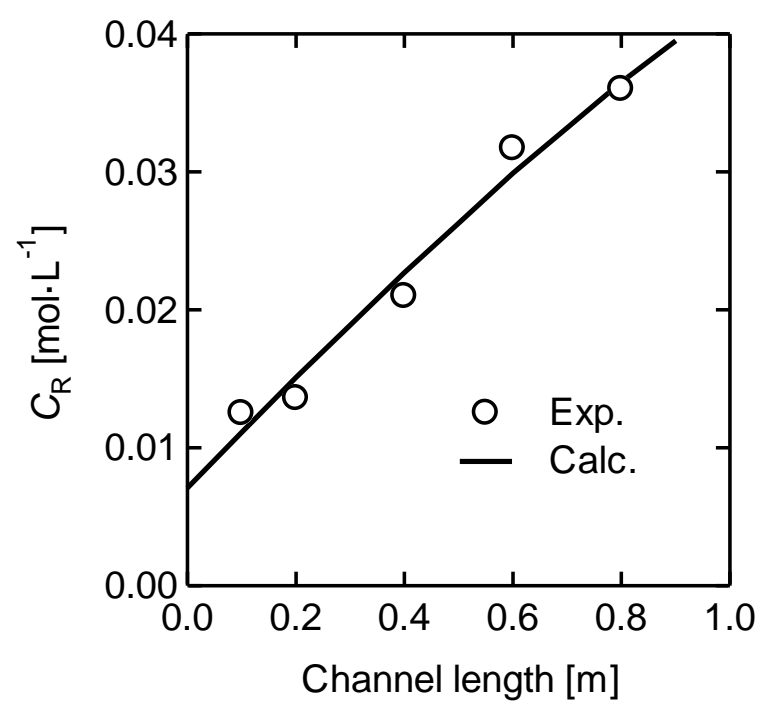

Fig. 9. 


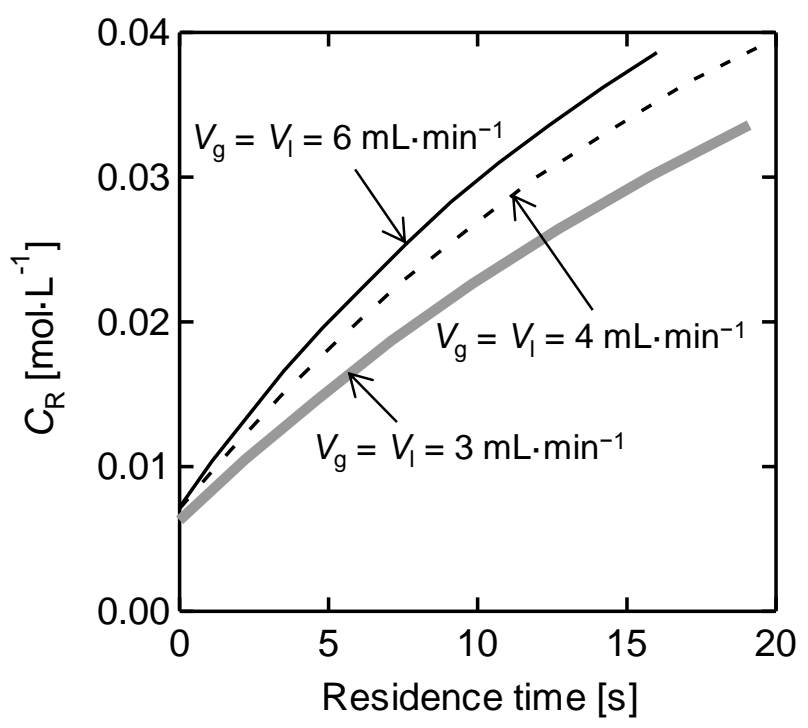

Fig. 10 . 


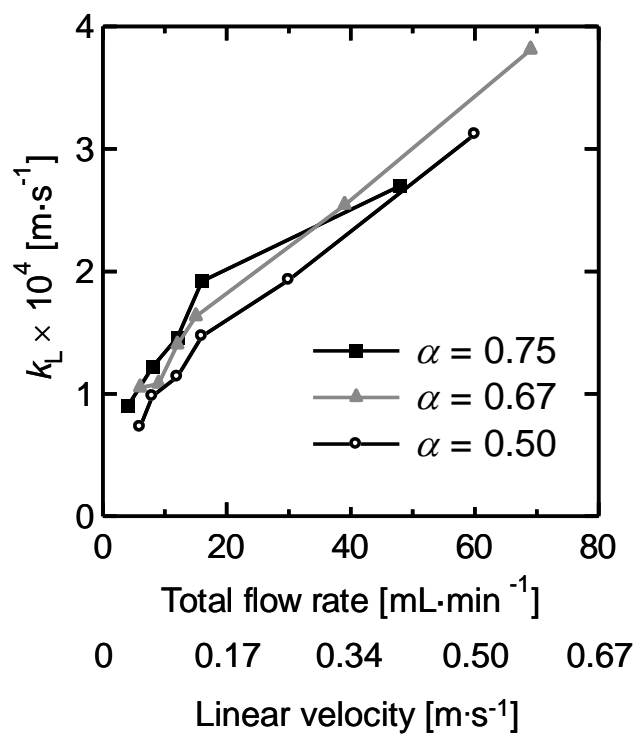

Fig. 11. 


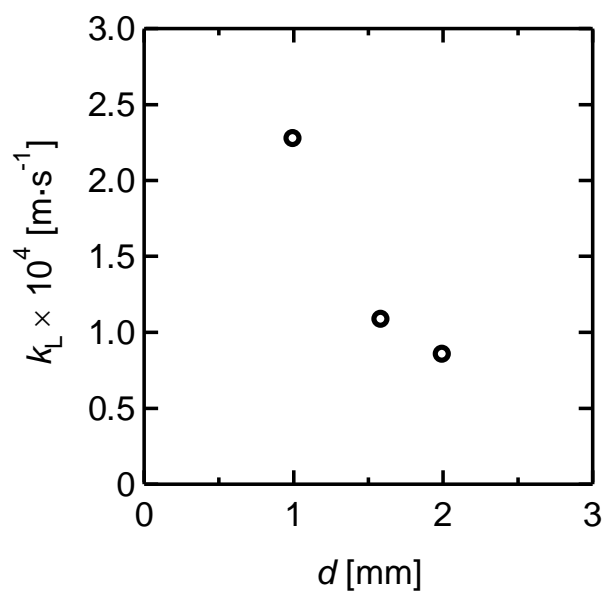

Fig. 12. 


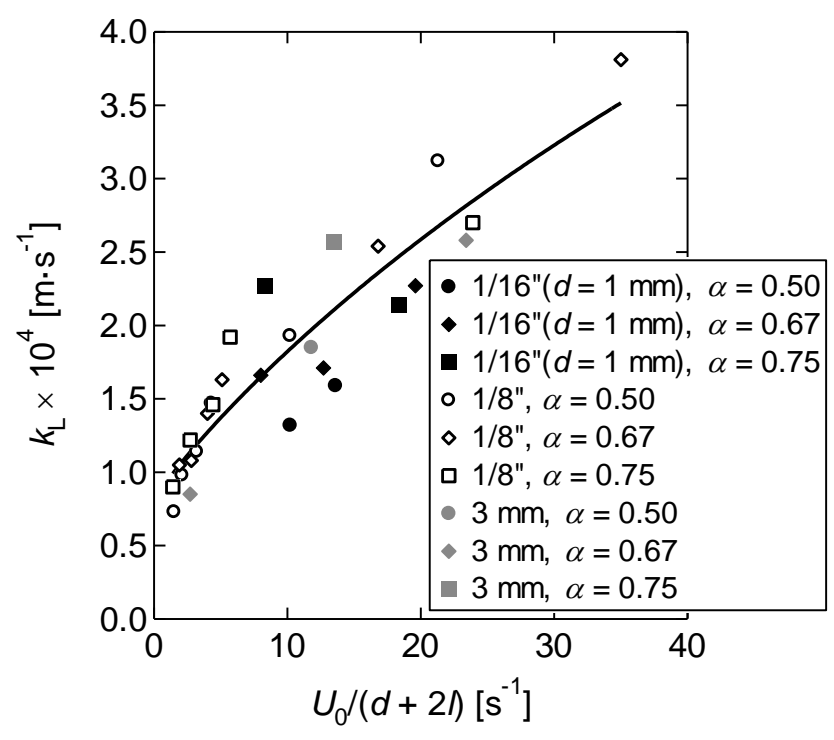

Fig. 13. 


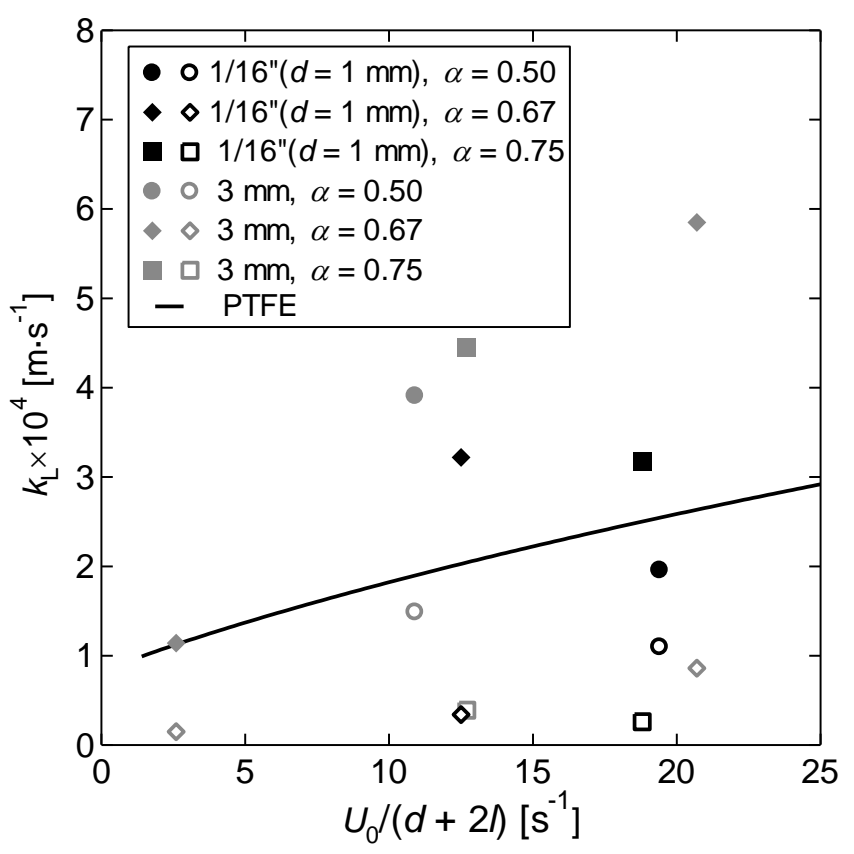

Fig. 14. 


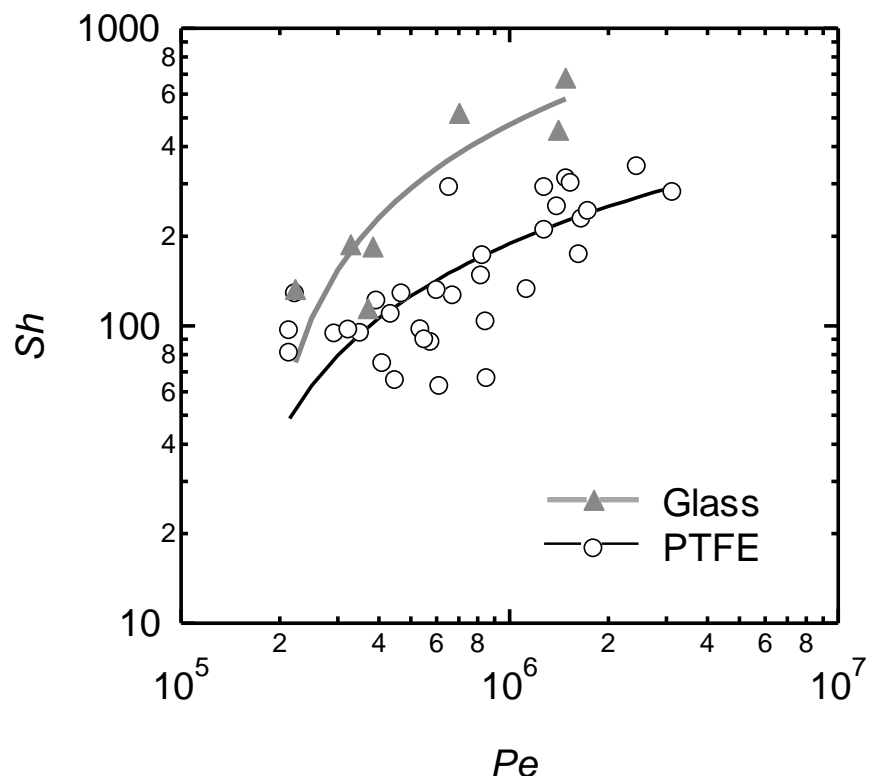

Fig. 15. 


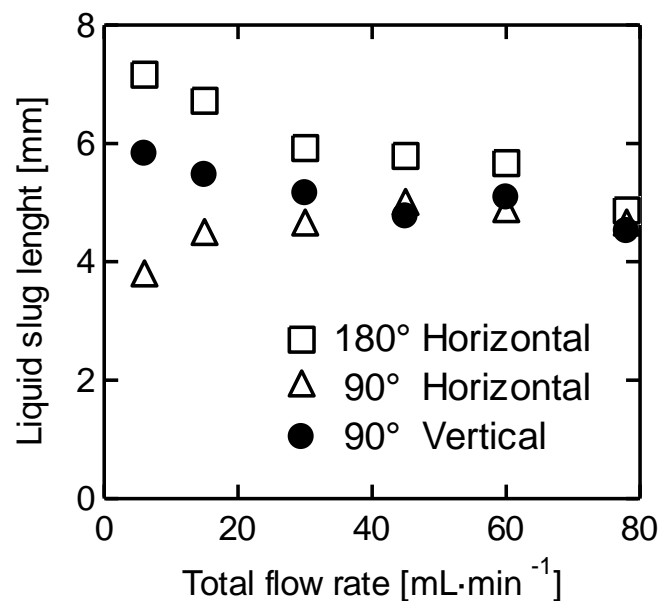

Fig. 16. 


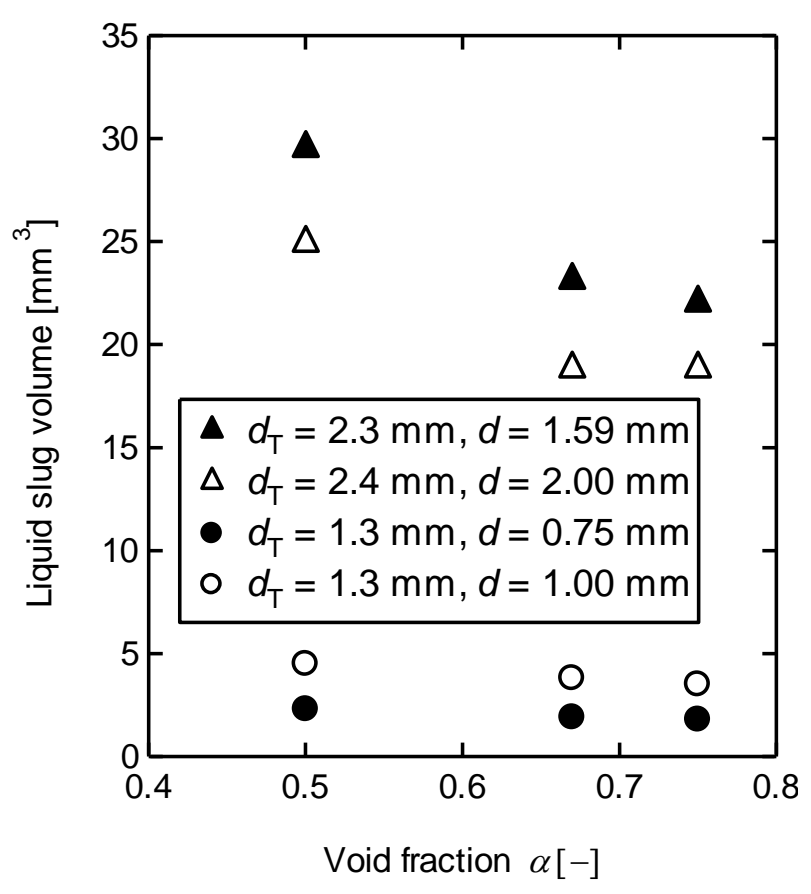

Fig. 17. 


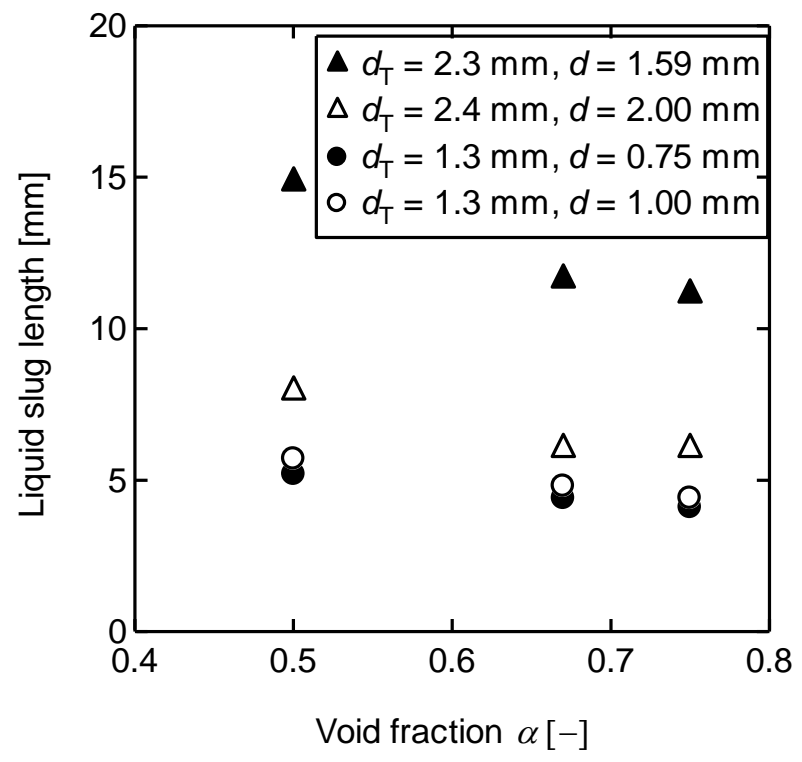

Fig. 18. 